Citing a recent paper (4) on the Two-County trial, he claims that "the study group had an excess of $28 \%$ in tumors larger than $2 \mathrm{~cm}$ (13.1 v. 10.2/1000 women)" (the italics are Dr. Skrabanek's). In fact, not only is this result absent from the paper cited, almost the opposite result was observed. There was a deficit of $26 \%$ in the study group in tumors at Stage II or worse, 5.9/1000 women in the study group, as compared to 8.0 in the control. Skrabanek is entitled to criticize the work of other researchers, but he would be well advised to read it first.

Finally, Skrabanek describes the Malmo trial as "perfect in design and execution." Readers unfamiliar with this area of research should not conclude that this is established fact. Reservations have been expressed about the Malmo trial, notably the low response rate, the contamination of the control group by treatment and the optimistic power/sample size projections (3). It is not our purpose to attack the Malmo trial here. The point is that no study is perfect, and to categorize a trial as such because its results agree with one's own opinions is evidence of the wishful thinking which Dr. Skrabanek is so quick to diagnose in others.

\author{
LASZLO TABAR \\ Mammography Department \\ Central Hospital \\ Falun 79182 \\ Sweden
}

Stephen W. Duffy and Nicholas E. Day MRC Biostatistics Unit

Cambridge CB2 $2 B W$

U.K.

\title{
REFERENCES
}

1. Clayton, D., \& Kaldor J. Empirical Bayes estimates of age-standardized relative risks for use in disease mapping. Biometrics, 1987, 43, 671-681.

2. Skrabanek, P. Mass mammography: The time for reappraisal. International Journal of Technology Assessment in Health Care, 1989, 5, 423-430.

3. Tabar, L., \& Duffy, S. W. Malmo mammographic screening trial [letter]. British Medical Journal, 1989, 298, 48-49.

4. Tabar, L., Fagerberg, C. J. G., \& Day, N. E. The results of periodic, one view mammography screening in a randomized, controlled trial in Sweden. Part II. Evaluation of the results. In N. E. Day \& A. B. Miller (Eds.), Screening for breast cancer. Toronto: Huber, 1988, 39-44.

5. Tabar, L., Fagerberg, G., Duffy, S. W., \& Day, N. E. The Swedish two-county trial of mammographic screening for breast cancer: recent results and calculation of benefit. Journal of Epidemiology and Community Health, 1989, 43, 107-114.

6. Tabar, L., Fagerberg, C. J. G., Gad, A., et al. Reduction in mortality from breast cancer after mass screening with mammography. Lancet, 1985, $i, 829-832$.

\section{SKRABANEK'S RESPONSE}

It is not surprising that Dr. Tabar and his colleagues, in view of their commitment to screening, did not like what I wrote (Skrabanek, P. Mass mammography: The time for reappraisal. IJTAHC, 1989, 5, 423-30). However, in their defense, they avoid answering the main points of my criticism: that is, the diminished impact of screening 
with the increasing sophistication of mammography, accompanied with increasing overdiagnosis; the confusion between statistical and clinical significance; keeping silence about adverse effects of mammography when selling screening to the public, and the ethical vacuum in which screening is marketed.

Randomization by cluster may be "respectable," but it is no substitute for proper individual randomization. This has again been shown in the ill-fated Edinburgh trial just published (1). The authors used also randomization by clusters only to realize too late that the mammography group and the control group were not comparable. In fact, the mammography group had a mortality rate from all causes $20 \%$ lower than the control group, leading to the paradoxical finding that proportionally more women died of breast cancer in the mammography group $(5.34 \%)$ than in the control group $(5.10 \%)$.

The reference to the excess of tumors larger than $2 \mathrm{~cm}$ in the study group is my error, for which I sincerely apologize. It arose by subtracting the rate of invasive tumors smaller than $2 \mathrm{~cm}$ (without axillary sampling) from the rate of all invasive tumors, in Table 4 of the original report by Tabar et al. (3).

In the conclusion of the Edinburgh report (1), the authors state that if the defects in their trial were to persist in population screening, resources would be spent recklessly and to little or no effect. This was an honest appraisal of yet another trial that failed to demonstrate a benefit to women offered by mammography. The first author, Dr. Maureen Roberts, in a separate communication (2), written on her deathbed, provided a frank account of the false hopes created by screening enthusiasts and on the politics behind the scenes. Roberts developed breast cancer while in charge of the Edinburgh program and died of the disease in June 1989. Her analysis, from the trenches, so to speak, was concordant with mine, from the armchair. "We can no longer ignore the possibility that screening may not reduce mortality in women of any age, however disappointing this may be" (2).

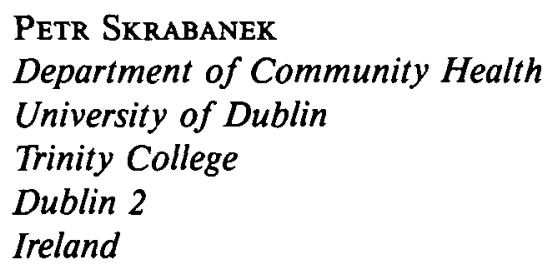

\section{REFERENCES}

1. Roberts M. M., Alexander F. E., Anderson T. J., et al. Edinburgh trial of screening for breast cancer: Mortality at seven years. Lancet, 1990, 335: 241-246.

2. Roberts M. M. Breast screening: Time for a rethink. British Medical Journal, 1989, 299: 1153-1155.

3. Tabar L., Fagerberg C. J. G., Gad A., et al. Reduction in mortality from breast cancer after mass screening with mammography. Lancet, 1985, $i$ : 829-832. 